\section{IJDMT}

(C) I A E M E

\title{
DEVELOPMENT OF MODELS USING GENETIC PROGRAMMING FOR TURNING INCONEL 718 WITH COATED CARBIDE TOOLS
}

\author{
M Manohar ${ }^{1}$ \\ Jomy Joseph ${ }^{2}$ \\ T Selvaraj ${ }^{3}$ \\ D Sivakumar ${ }^{1}$ \\ 1 Scientist/Engineer, Vikram Sarabhai Space Centre (ISRO) Trivandrum, India \\ 2 Assistant Professor, Viswajyothi College of Engg. and Technology, Muvattupuzha, India \\ 3 Professor, National Institute of Technology, Tiruchirappalli, India \\ Corresponding author: manohar_isro@yahoo.com
}

\begin{abstract}
This paper discusses the methodology of developing models for the turning process for machining Inconel 718 alloy with coated carbide tool inserts. Approach through Genetic programming (GP) was aimed at with an overall objective of optimizing the process to yield higher metal removal, better surface quality and lower cutting forces. Taguchi's approach was adopted for the design of experiments and accordingly experiments were carried out, for collecting experimental data in a controlled manner. Such data was grouped separately at random for training genetic models (the models developed using GP) and further validating them. Models generated establish relationship between the input parameters with the output parameter and also show the order of dominance of the input parameters. Prediction of the output parameters is in fair comparison with the actual measured values. For easy understanding and explicit depiction, plots were made for each output parameter. Plots made show the trend of the prediction capability of the models in both the training set and validation set of data; further the plots exhibit the trend of variables' interaction in the process.

This work resulted in developing models for the turning process for Inconel 718 Alloy in a scientific manner. It also enables identifying the optimised set of turning parameters for Inconel 718 material using coated carbide tools, to achieve better surface roughness and higher material removal. This work gains significance in the sense with reasonably minimum number of experiments, reliable model has been generated, validated and further, the process has been optimised with two objectives (viz. improved quality and higher productivity).
\end{abstract}

Key words: optimisation, Inconel 718, Genetic programming, models, coated carbide tools 
International Journal of Design and Manufacturing Technology (IJDMT), ISSN 0976 - 6995(Print), ISSN 0976 - 7002(Online) Volume 4, Issue 1, January- April (2013), @ IAEME

\subsection{INTRODUCTION}

Inconel 718 is the widely used high-performance material, which withstands stringent operating conditions in aerospace, automobile, nuclear power and thermal power industries. With an increase in demand for the material in many applications, focusing of efforts to minimize the cycle-time to manufacture the component gains significance. Machining of such super-alloys to the desired configuration continues to be the challenge in the shop-floor and researchers constantly address such challenges and come-out with innovative solutions. Over the years, developments that have taken place in the machining of Inconel 718 material have considerably reduced its machining difficulties. Challenges in machining, which are hallmark of super-alloys, are occurrence of multiple wear mechanisms in cutting tool failure, damage to machined surfaces that extends to the sub-surface levels in certain cases, and development of intense shear in the chip formation [1-6].

Machinability of a material is the ability of the work material to get machined. To assess the machinability of a material, the four main parameters to be considered are (i) tool life (ii) surface finish and (iii) material removal rate (iv) cutting forces. Heat resistant super alloys possess specific characteristics that are detrimental to their machinability. The metallurgical characteristics responsible for the good strength and creep resistance of nickel base super alloys at high temperatures are responsible for their being difficult to machine. These materials work harden rapidly during machining. Other factors such as low thermal diffusivity and the presence of carbide particles are also responsible for their poor machinability.

Quality of the machined surface is characterized by surface roughness and metallurgical surface damage, which are together termed as 'surface integrity'. Surface integrity has significant influence on the surface sensitive properties such as fatigue, stress corrosion resistance and creep strength, which are directly related to the service-life of the components [7]. Hence, high degree of surface integrity is a prime requirement for better performance, reliability and longevity of the machined parts during service. Cutting forces generated during machining play an important role in the generation of stresses and temperature over the machined surfaces and along tool-chip and tool-work interfaces [8.9]. The above effects combinedly result in poor surface integrity on the machined component, which adversely affect the performance of the component during its intended services. Hence, it is important to focus on addressing the contributing factors to reduce such ill-effects of the machined component. It has been demonstrated that the machining parameters directly influence the cutting forces and it is possible to generate favorable surface characteristics, by choosing appropriate set of machining parameters [9]. Further, newer techniques on machining like taper turning (ramping), coolant delivery at high pressure, hot machining, cryo-aided machining and adoption of self-propelled rotary tooling have been developed over the years for improving the quality of machined surface. Thorough understanding of the work-material characteristics, its behavior, and its relationship with cutting tool materials, machining conditions and the influence of process parameters shall enable to achieve optimised cutting process.

Machinability model is expressed as a functional relationship involving the machining parameters (speed, feed, depth of cut) otherwise known as the input variables and the output parameters (tool life, surface finish, cutting force, residual stress, surface temperature) otherwise known as the responses of a machining process [10-13] . For developing such a model, it is essential to design and carry out an experimental study selecting the work material, the cutting tool and machining conditions. The experimental study generates the 
International Journal of Design and Manufacturing Technology (IJDMT), ISSN 0976 - 6995(Print), ISSN 0976 - 7002(Online) Volume 4, Issue 1, January- April (2013), @ IAEME

response data as a function of machining parameters (input variables) viz. cutting speed, feed rate, and depth of cut.

This work makes use of Taguchi method for optimizing the machining parameters while machining Inconel 718 alloy, which is an attractive and effective method to deal with the responses influenced by number of input-variables. This method assumes the chosen machining parameters to have influence on process outcome that are located at different rows in a designed orthogonal array [14-17]. With the above arrangement thoroughly randomized experiments are conducted. Further, this method is useful for studying the effect of interactions among the chosen parameters, and this is a powerful experimental design tool, capable of providing a simple, efficient and systematic approach to arrive at optimum machining parameters. In comparison with the conventional approach of experimental design, this method considerably reduces the number of experiments that are needed to model the output parameters (responses) [14, 15]. It is always proposed for the purpose of improving the quality of machining process based on the concepts of statistics and engineering [15].

In order to get improved surface quality and reduced cutting forces, it is prudent to adopt analytical methods to determine optimal machining parameters by establishing the method for predicting the responses [11]. For this purpose, Genetic programming (GP) is used that gives a mathematical model relating the input variables and the output parameter. The model is validated using the experimental data collected and further it predicts the output for the given set of input variable.

GP is a method to evolve computer programs. In artificial intelligence, GP is an evolutionary algorithm-based methodology inspired by biological evolution to find computer programs that perform a user-defined task. It is a specialization of genetic algorithms (GA) where each individual is a computer program. It is a machine learning technique used to optimize a population of computer programs according to a fitness landscape determined by a program's ability to perform a given computational task $[18,19]$. GP and a similar tool GONNS (Genetically Optimized Neural Network System) are the machine learning techniques used to optimize a population of computer programs according to a fitness landscape determined by a program's ability to perform a given computational task [18-23].

\subsection{EXPERIMENT DETAILS}

Inconel 718 alloy in the form of cylindrical work piece of $60 \mathrm{~mm}$ diameter in the annealed condition was chosen as the work material for the experimental study.

Cutting Tool Inserts of 'Kennametal' make, Grade HK 150 (Trade mark) was used for the machining experiments. It is a fine-grained tungsten carbide 6\% Cobalt substrate with a CVD Multilayer coating. The coating layers are TiN/TiCN/Al2O3 with a total thickness of $12 \mu \mathrm{m}$.

Machining experiments were conducted in a CNC turning centre. Work-piece was machined for a width of $12 \mathrm{~mm}$ (appears like a ring), for each set of machining parameters and machining of 27 such rings were done and identified in the same order, as shown in Figure -1. Machining was carried

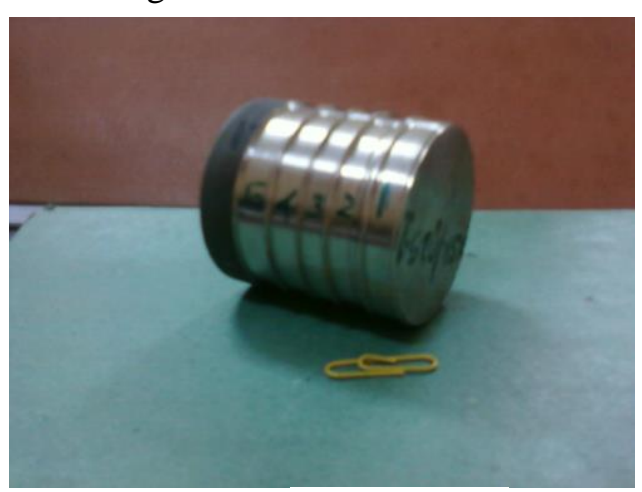

out with each set of parameters once and the cutting force, surface roughness values were measured as output parameters (responses) of the single experiment. Output parameters for each set of input variables were measured and they were taken as actual values for comparing with the predicted values.

Figure -1 
International Journal of Design and Manufacturing Technology (IJDMT), ISSN 0976 - 6995(Print), ISSN 0976 - 7002(Online) Volume 4, Issue 1, January- April (2013), @ IAEME

\subsection{Design of Experiments}

The Taguchi method is widely used in engineering analysis. The methodology incorporates a series of experiments with the objective of acquiring data in a controlled manner, carrying out these experiments to obtain information about the behavior of a given process.

The experiments were planned and executed using Taguchi's orthogonal array, in the design of experiments $[16,17]$. Surface roughness of the component while turning is known to be influenced in varying amounts by a number of factors like feed rate, work material characteristics, cutting speed, depth of cut, tool nose radius and tool cutting edge angles [24 - 26]. Machining parameters' influence or effect on the work material is represented by cutting force acting on the tool-tip [9].

For assessing the machinability of the work-material, or the performance of the cutting tool inserts, output parameters (responses) considered are cutting force, temperature on the cutting tool and the work, surface roughness, residual stress and tool wear [4, 7, 9-11, 24-26]. It is observed from the shop-floor practices and the literatures available that surface roughness is the factor which reflects the effect of all the other output parameters and the cutting forces precisely reflect the influence of input parameters over the machining conditions. Accordingly for the present investigation, the machining parameters viz. cutting speed (v), feed rate (f) and depth of cut (d) were taken as the input parameters for the process and the output parameters as surface roughness (Ra) and the cutting forces namely Feed Force (Fx), Cutting Force (Fy) and Thrust Force (Fz).

Since the considered factors were multi-level variables and their effects were not linearly related, it was decided to use three level tests for each factor [5, 27].

The levels were fixed after preliminary studies, review of available literatures and the data sheet on cutting tool inserts, which have been recently developed. Experiments at preliminary level were conducted at wider range of machining parameters and the surface finish of the machined surface was measured. Lower ranges of the parameters were not considered since the MRR was low and higher ranges were not considered since operating at these levels resulted in poor surface finish, faster tool wear and chatter. Considering the practical conditions of achievable limit of MRR coupled with moderate range of Surface finish and cutting forces, the levels of the machining parameters for the experiment was chosen. The factors considered for the study and the assignment of corresponding values for the factors are detailed in Table-1 [28-29].

Table 1 Value of Input parameters at 3 levels

\begin{tabular}{|cccc|}
\hline Levels & $\begin{array}{c}\text { Cutting speed } \\
(\mathrm{m} / \mathrm{min})\end{array}$ & $\begin{array}{c}\text { Feed } \\
(\mathrm{mm} / \mathrm{rev})\end{array}$ & $\begin{array}{c}\text { Depth of cut } \\
(\mathrm{mm})\end{array}$ \\
\hline Level 1 & 40 & 0.20 & 1.0 \\
Level 2 & 50 & 0.25 & 1.5 \\
Level 3 & 60 & 0.30 & 2.0 \\
\hline
\end{tabular}

Taguchi's orthogonal array of L27 is the most suitable for this experiment, which needs 27 runs and has 26 degrees of freedom (DOF).The coded input values of machining parameters and the measured values of output parameters are listed in Table- $2[28,29]$.

\subsection{Experimental Set-up}

CNC lathe was fitted with the KISTLER dynamometer (KISTLER 9121B Model) and during machining of each region, cutting forces were measured and recorded. Measured values of components of Cutting forces Fx, Fy and Fz have been presented in Table - 2. Each ring of the machined work-piece was subjected to Surface roughness (Ra) measurements using 'FORM TALYSURF' (Taylor-Hobson make), whose accuracy is $2 \%$ of the indicated reading. Surface roughness measurements were measured on each machined region and assessed to ensure that the dispersion is controlled and well within the normal dispersion; minimum of the three values for each surface was taken for analysis purposes and given in Table-2. For each set of input parameters MRR was calculated and given in Table-2. 
International Journal of Design and Manufacturing Technology (IJDMT), ISSN 0976 - 6995(Print), ISSN 0976 - 7002(Online) Volume 4, Issue 1, January- April (2013), @ IAEME

Table 2 Experimental conditions and results

\begin{tabular}{|c|c|c|c|c|c|c|c|c|}
\hline \multirow[t]{3}{*}{$\begin{array}{l}\text { Sl. } \\
\text { No. }\end{array}$} & \multicolumn{3}{|c|}{$\begin{array}{c}\text { Input variables } \\
\text { (coded values) }\end{array}$} & \multicolumn{5}{|c|}{ Experimental Results } \\
\hline & \multirow{2}{*}{$\begin{array}{c}\mathbf{v} \\
\mathrm{m} / \mathrm{min}\end{array}$} & \multirow{2}{*}{$\begin{array}{c}\mathbf{f} \\
\mathrm{mm} / \mathrm{rev}\end{array}$} & \multirow{2}{*}{$\begin{array}{c}\mathbf{d} \\
\mathbf{m m}\end{array}$} & \multirow{2}{*}{$\begin{array}{c}\mathbf{R a} \\
(\mu \mathbf{m})\end{array}$} & \multicolumn{3}{|c|}{ Cutting Force (N) } & \multirow{2}{*}{$\begin{array}{c}\text { MRR } \\
\mathrm{mm}^{3} / \mathrm{min} \\
\end{array}$} \\
\hline & & & & & $\mathbf{F x}$ & Fy & $\mathbf{F z}$ & \\
\hline 1 & 1 & 1 & 1 & 3.12 & 168 & 41 & 66 & 8000 \\
\hline 2 & 1 & 1 & 2 & 3.15 & 178 & 45 & 70 & 12000 \\
\hline 3 & 1 & 1 & 3 & 3.22 & 192 & 52 & 75 & 16000 \\
\hline 4 & 1 & 2 & 1 & 3.24 & 179 & 47 & 69 & 10000 \\
\hline 5 & 1 & 2 & 2 & 3.37 & 190 & 53 & 74 & 15000 \\
\hline 6 & 1 & 2 & 3 & 3.42 & 201 & 58 & 80 & 20000 \\
\hline 7 & 1 & 3 & 1 & 3.60 & 213 & 65 & 85 & 12000 \\
\hline 8 & 1 & 3 & 2 & 3.71 & 222 & 71 & 89 & 18000 \\
\hline 9 & 1 & 3 & 3 & 3.76 & 231 & 78 & 95 & 24000 \\
\hline 10 & 2 & 1 & 1 & 2.98 & 160 & 36 & 59 & 10000 \\
\hline 11 & 2 & 1 & 2 & 3.09 & 171 & 42 & 64 & 15000 \\
\hline 12 & 2 & 1 & 3 & 3.13 & 180 & 48 & 68 & 20000 \\
\hline 13 & 2 & 2 & 1 & 3.20 & 174 & 44 & 62 & 12500 \\
\hline 14 & 2 & 2 & 2 & 3.25 & 182 & 48 & 69 & 18750 \\
\hline 15 & 2 & 2 & 3 & 3.32 & 191 & 54 & 73 & 25000 \\
\hline 16 & 2 & 3 & 1 & 3.56 & 204 & 60 & 79 & 15000 \\
\hline 17 & 2 & 3 & 2 & 3.69 & 211 & 68 & 86 & 22500 \\
\hline 18 & 2 & 3 & 3 & 3.75 & 220 & 75 & 91 & 30000 \\
\hline 19 & 3 & 1 & 1 & 3.08 & 152 & 33 & 55 & 12000 \\
\hline 20 & 3 & 1 & 2 & 3.01 & 160 & 39 & 60 & 18000 \\
\hline 21 & 3 & 1 & 3 & 3.07 & 169 & 46 & 64 & 24000 \\
\hline 22 & 3 & 2 & 1 & 3.15 & 170 & 40 & 58 & 15000 \\
\hline 23 & 3 & 2 & 2 & 3.20 & 177 & 44 & 63 & 22500 \\
\hline 24 & 3 & 2 & 3 & 3.28 & 185 & 49 & 67 & 30000 \\
\hline 25 & 3 & 3 & 1 & 3.49 & 191 & 52 & 65 & 18000 \\
\hline 26 & 3 & 3 & 2 & 3.60 & 199 & 57 & 71 & 27000 \\
\hline 27 & 3 & 3 & 3 & 3.71 & 209 & 63 & 78 & 36000 \\
\hline
\end{tabular}


International Journal of Design and Manufacturing Technology (IJDMT), ISSN 0976 - 6995(Print), ISSN 0976 - 7002(Online) Volume 4, Issue 1, January- April (2013), @ IAEME

From the above set of experimental data collected, two sub-sets of data were grouped selecting at random, one sub-set (Table-3) for training the model and the other sub-set (Table- 4) for testing (validating) the model.

Table -3 Training Data set

\begin{tabular}{|c|c|c|c|c|c|c|c|}
\hline \multirow{3}{*}{$\begin{array}{l}\text { Sl. } \\
\text { No. }\end{array}$} & \multicolumn{3}{|c|}{ Input variables } & \multicolumn{4}{|c|}{ Experimental Results } \\
\hline & \multirow{2}{*}{$\begin{array}{c}\mathbf{v} \\
\mathrm{m} / \mathrm{min}\end{array}$} & \multirow{2}{*}{$\begin{array}{c}\mathbf{f} \\
\mathrm{mm} / \mathrm{rev}\end{array}$} & \multirow{2}{*}{$\begin{array}{c}\mathrm{d} \\
\mathbf{m m}\end{array}$} & \multirow{2}{*}{$\begin{array}{c}\mathbf{R a} \\
(\boldsymbol{\mu m})\end{array}$} & \multicolumn{3}{|c|}{ Cutting Force (N) } \\
\hline & & & & & $\mathbf{F x}$ & Fy & $\mathbf{F z}$ \\
\hline 1 & 40 & 0.2 & 1.0 & 3.12 & 168 & 41 & 66 \\
\hline 2 & 40 & 0.2 & 1.5 & 3.15 & 178 & 45 & 70 \\
\hline 3 & 40 & 0.25 & 1.5 & 3.37 & 190 & 53 & 74 \\
\hline 4 & 40 & 0.25 & 2.0 & 3.42 & 201 & 58 & 80 \\
\hline 5 & 40 & 0.3 & 1.0 & 3.60 & 213 & 65 & 85 \\
\hline 6 & 40 & 0.3 & 2.0 & 3.76 & 231 & 78 & 95 \\
\hline 7 & 50 & 0.2 & 1.5 & 3.09 & 171 & 42 & 64 \\
\hline 8 & 50 & 0.2 & 2.0 & 3.13 & 180 & 48 & 68 \\
\hline 9 & 50 & 0.25 & 1.0 & 3.20 & 174 & 44 & 62 \\
\hline 10 & 50 & 0.25 & 2.0 & 3.32 & 191 & 54 & 73 \\
\hline 11 & 50 & 0.3 & 1.0 & 3.56 & 204 & 60 & 79 \\
\hline 12 & 50 & 0.3 & 1.5 & 3.69 & 211 & 68 & 86 \\
\hline 13 & 60 & 0.2 & 1.0 & 3.08 & 152 & 33 & 55 \\
\hline 14 & 60 & 0.2 & 2.0 & 3.07 & 169 & 46 & 64 \\
\hline 15 & 60 & 0.25 & 1.0 & 3.15 & 170 & 40 & 58 \\
\hline 16 & 60 & 0.25 & 1.5 & 3.20 & 177 & 44 & 63 \\
\hline 17 & 60 & 0.3 & 1.5 & 3.60 & 199 & 57 & 71 \\
\hline 18 & 60 & 0.3 & 2.0 & 3.71 & 209 & 63 & 78 \\
\hline
\end{tabular}


International Journal of Design and Manufacturing Technology (IJDMT), ISSN 0976 - 6995(Print), ISSN 0976 - 7002(Online) Volume 4, Issue 1, January- April (2013), @ IAEME

Table -4 Validation Data set

\begin{tabular}{cccccccc}
\hline Sl. & \multicolumn{3}{c}{ Input variables } & \multicolumn{5}{c}{ Experimental Results } \\
\cline { 6 - 9 } & $\begin{array}{c}\mathbf{v} \\
\mathbf{m} / \mathbf{m i n}\end{array}$ & $\begin{array}{c}\mathbf{f} \\
\mathbf{m m} / \mathbf{r e v}\end{array}$ & $\begin{array}{c}\mathbf{d} \\
\mathbf{m m}\end{array}$ & $\begin{array}{c}\mathbf{R a} \\
(\boldsymbol{\mu m})\end{array}$ & \multicolumn{2}{c}{ Cutting Force (N) } \\
\cline { 6 - 9 } 1 & 40 & 0.2 & 2.0 & 3.22 & 192 & 52 & 75 \\
2 & 40 & 0.25 & 1.0 & 3.24 & 179 & 47 & 69 \\
3 & 40 & 0.3 & 1.5 & 3.71 & 222 & 71 & 89 \\
4 & 50 & 0.2 & 1.0 & 2.98 & 160 & 36 & 59 \\
5 & 50 & 0.25 & 1.5 & 3.25 & 182 & 48 & 69 \\
6 & 50 & 0.3 & 2.0 & 3.75 & 220 & 75 & 91 \\
7 & 60 & 0.2 & 1.5 & 3.01 & 160 & 39 & 60 \\
8 & 60 & 0.25 & 2.0 & 3.28 & 185 & 49 & 67 \\
9 & 60 & 0.3 & 1.0 & 3.49 & 191 & 52 & 65
\end{tabular}

\subsection{GENETIC MODELS}

Mathematical model is a collection of statistical and mathematical techniques used for developing, improving and optimizing process variables; this is dedicated to the evaluation of relations existing between a group of controlled experimental factors and the observed results of one or more selected criteria. Genetic programming evolves a group of techniques used in empirical study of the relationship between a response and several input variables [18].

Selection of the function-set included plus, minus, multiply, divide, power and square. Evolutionary parameters used in the development of models were of, population size $=96$, number of generations $(\max )=$.30 , depth of tree $(\max )=$.200 , number of identical chromosomes $(\max )=$.2 , length of chromosome $(\max )=$.30 and tournament size $=3$. With the randomly selected group of experimental data, by varying fitness constants through numerous iterations, using Genetic Modeling System (GeMS) software, the Genetic Models were obtained.

Mathematical models obtained through genetic programming called Genetic Models are given below.

Surface Roughness is given by

$$
R a=-0.0051 v-17.52 f-0.27 d+41.34 f^{2}+1.55 f d+5.154
$$

Feed Force (Fx) is given by

$$
F x=2633 f^{2}+16.67 d-0.875 v-901.7 f+263.4
$$

Cutting Force (Fy) is given by

$$
F y=1.03 v+11 d+7520 \frac{f}{v+356.1-1106 f}-0.0131 v^{2}
$$

Thrust Force $\mathrm{Fz}$ is given by

$$
F z=-2.74 v f+12502 f^{5}+34.45 f d+77.45
$$

The models were compared within the training set of data to assess their fitness and further they were validated using the independent data sets called 'validation data sets'. 
International Journal of Design and Manufacturing Technology (IJDMT), ISSN 0976 - 6995(Print), ISSN 0976 - 7002(Online) Volume 4, Issue 1, January- April (2013), @ IAEME

\subsection{RESULTS AND DISCUSSIONS}

Models generated for each output parameter (response) establish the relationship between the variable input parameters and the output parameter. The models generated for the output parameters, allow the users to obtain the optimal set of machining parameters and also show the order of their influence on the output parameter.

In all the above models feed rate (f) is the dominant factor that influences the output parameter followed by depth of cut (d) and cutting velocity (v). Though for the cutting force (Fy), Equation (3) shows that cutting velocity term is in the second order and feed rate term in the first order due to the effect of respective co-efficient, the feed rate term is only dominant. The above models help to choose the set of input parameters, considering the preference of the user for higher material removal rate or improved quality of the machined surface coupled with longer tool-life (effect of lower cutting forces).

Predicted values using the above models were compared with the actual values of training data set (Table-5) and majority of the 18 sets of values are well within $1 \%$ variation and few sets have gone to an extent of $3 \%$ variation. Further these models were verified with the independent set of experimental data called validation data set (Table-6). It is observed that majority of the 9 sets of values are well within 3\% variation and few sets fall within the accuracy limit of $6 \%$. This clearly shows that the experiments have been conducted for all sets of input variables in a controlled manner and the measurement errors are within the permissible limits. Secondly, the models developed through Genetic Programming are dependable since their fitness quality within the data chosen for training them is high. In addition, these models were validated using independent Data sets and for these data sets also the comparison between predicted and actual values are well with in the acceptable range.

Table 5 Comparison of Predicted values with Experimental values (Training Data Set)

\begin{tabular}{|c|c|c|c|c|c|c|c|c|c|c|}
\hline \multicolumn{3}{|c|}{ Input variables } & \multicolumn{4}{|c|}{ Experimental values } & \multicolumn{4}{|c|}{ Predicted values } \\
\hline \multirow{2}{*}{$\begin{array}{c}\mathrm{v} \\
\mathrm{m} / \mathrm{min}\end{array}$} & \multirow{2}{*}{$\begin{array}{c}\mathrm{f} \\
\mathrm{mm} / \mathrm{rev}\end{array}$} & \multirow{2}{*}{$\underset{\mathrm{mm}}{\mathrm{d}}$} & \multirow{2}{*}{$\begin{array}{c}\mathrm{Ra} \\
(\mu \mathrm{m})\end{array}$} & \multicolumn{3}{|c|}{ Cutting Forces $(\mathrm{N})$} & \multirow{2}{*}{$\begin{array}{c}\mathrm{Ra} \\
(\mu \mathrm{m})\end{array}$} & \multicolumn{3}{|c|}{ Cutting Forces (N) } \\
\hline & & & & Fx & Fy & $\mathrm{Fz}$ & & Fx & Fy & $\mathrm{Fz}$ \\
\hline 40 & 0.2 & 1.0 & 3.12 & 168 & 41 & 66 & 3.14 & 170 & 40 & 66 \\
\hline 40 & 0.2 & 1.5 & 3.15 & 178 & 45 & 70 & 3.16 & 178 & 45 & 70 \\
\hline 40 & 0.25 & 1.5 & 3.37 & 190 & 53 & 74 & 3.33 & 193 & 52 & 75 \\
\hline 40 & 0.25 & 2.0 & 3.42 & 201 & 58 & 80 & 3.39 & 201 & 58 & 80 \\
\hline 40 & 0.3 & 1.0 & 3.60 & 213 & 65 & 85 & 3.61 & 212 & 66 & 85 \\
\hline 40 & 0.3 & 2.0 & 3.76 & 231 & 78 & 95 & 3.8 & 228 & 77 & 96 \\
\hline 50 & 0.2 & 1.5 & 3.09 & 171 & 42 & 64 & 3.11 & 170 & 43 & 64 \\
\hline 50 & 0.2 & 2.0 & 3.13 & 180 & 48 & 68 & 3.13 & 178 & 49 & 68 \\
\hline 50 & 0.25 & 1.0 & 3.20 & 174 & 44 & 62 & 3.22 & 175 & 44 & 64 \\
\hline 50 & 0.25 & 2.0 & 3.32 & 191 & 54 & 73 & 3.34 & 192 & 55 & 73 \\
\hline 50 & 0.3 & 1.0 & 3.56 & 204 & 60 & 79 & 3.56 & 203 & 60 & 77 \\
\hline 50 & 0.3 & 1.5 & 3.69 & 211 & 68 & 86 & 3.66 & 211 & 66 & 82 \\
\hline 60 & 0.2 & 1.0 & 3.08 & 152 & 33 & 55 & 3.04 & 153 & 33 & 55 \\
\hline 60 & 0.2 & 2.0 & 3.07 & 169 & 46 & 64 & 3.08 & 169 & 44 & 62 \\
\hline 60 & 0.25 & 1.0 & 3.15 & 170 & 40 & 58 & 3.17 & 167 & 39 & 57 \\
\hline 60 & 0.25 & 1.5 & 3.20 & 177 & 44 & 63 & 3.23 & 175 & 45 & 62 \\
\hline 60 & 0.3 & 1.5 & 3.60 & 199 & 57 & 71 & 3.6 & 202 & 58 & 74 \\
\hline 60 & 0.3 & 2.0 & 3.71 & 209 & 63 & 78 & 3.7 & 211 & 63 & 79 \\
\hline
\end{tabular}


International Journal of Design and Manufacturing Technology (IJDMT), ISSN 0976 - 6995(Print), ISSN 0976 - 7002(Online) Volume 4, Issue 1, January- April (2013), @ IAEME

Table 6 Comparison of Predicted values with Experimental values (Validation Data Set)

\begin{tabular}{|c|c|c|c|c|c|c|c|c|c|c|}
\hline \multicolumn{3}{|c|}{ Input variables } & \multicolumn{4}{|c|}{ Experimental values } & \multicolumn{4}{|c|}{ Predicted values } \\
\hline \multirow{2}{*}{$\begin{array}{c}\mathrm{v} \\
\mathrm{m} / \mathrm{min}\end{array}$} & \multirow{2}{*}{$\begin{array}{c}\mathrm{f} \\
\mathrm{mm} / \mathrm{rev}\end{array}$} & \multirow{2}{*}{$\begin{array}{c}\mathrm{d} \\
\mathrm{mm}\end{array}$} & \multirow{2}{*}{$\begin{array}{c}\mathrm{Ra} \\
(\mu \mathrm{m})\end{array}$} & \multicolumn{3}{|c|}{ Cutting Forces $(\mathrm{N})$} & \multirow{2}{*}{$\begin{array}{c}\mathrm{Ra} \\
(\mu \mathrm{m})\end{array}$} & \multicolumn{3}{|c|}{ Cutting Forces $(\mathrm{N})$} \\
\hline & & & & Fx & Fy & $\mathrm{Fz}$ & & $\mathrm{Fx}$ & Fy & $\mathrm{Fz}$ \\
\hline 40 & 0.2 & 2.0 & 3.22 & 192 & 52 & 75 & 3.18 & 187 & 51 & 73 \\
\hline 40 & 0.25 & 1.0 & 3.24 & 179 & 47 & 69 & 3.27 & 184 & 47 & 71 \\
\hline 40 & 0.3 & 1.5 & 3.71 & 222 & 71 & 89 & 3.71 & 220 & 72 & 90 \\
\hline 50 & 0.2 & 1.0 & 2.98 & 160 & 36 & 59 & 3.09 & 161 & 38 & 61 \\
\hline 50 & 0.25 & 1.5 & 3.25 & 182 & 48 & 69 & 3.28 & 184 & 50 & 68 \\
\hline 50 & 0.3 & 2.0 & 3.75 & 220 & 73 & 91 & 3.75 & 219 & 71 & 87 \\
\hline 60 & 0.2 & 1.5 & 3.01 & 160 & 39 & 60 & 3.06 & 161 & 39 & 59 \\
\hline 60 & 0.25 & 2.0 & 3.28 & 185 & 49 & 67 & 3.29 & 183 & 50 & 66 \\
\hline 60 & 0.3 & 1.0 & 3.49 & 191 & 52 & 65 & 3.51 & 194 & 52 & 69 \\
\hline
\end{tabular}

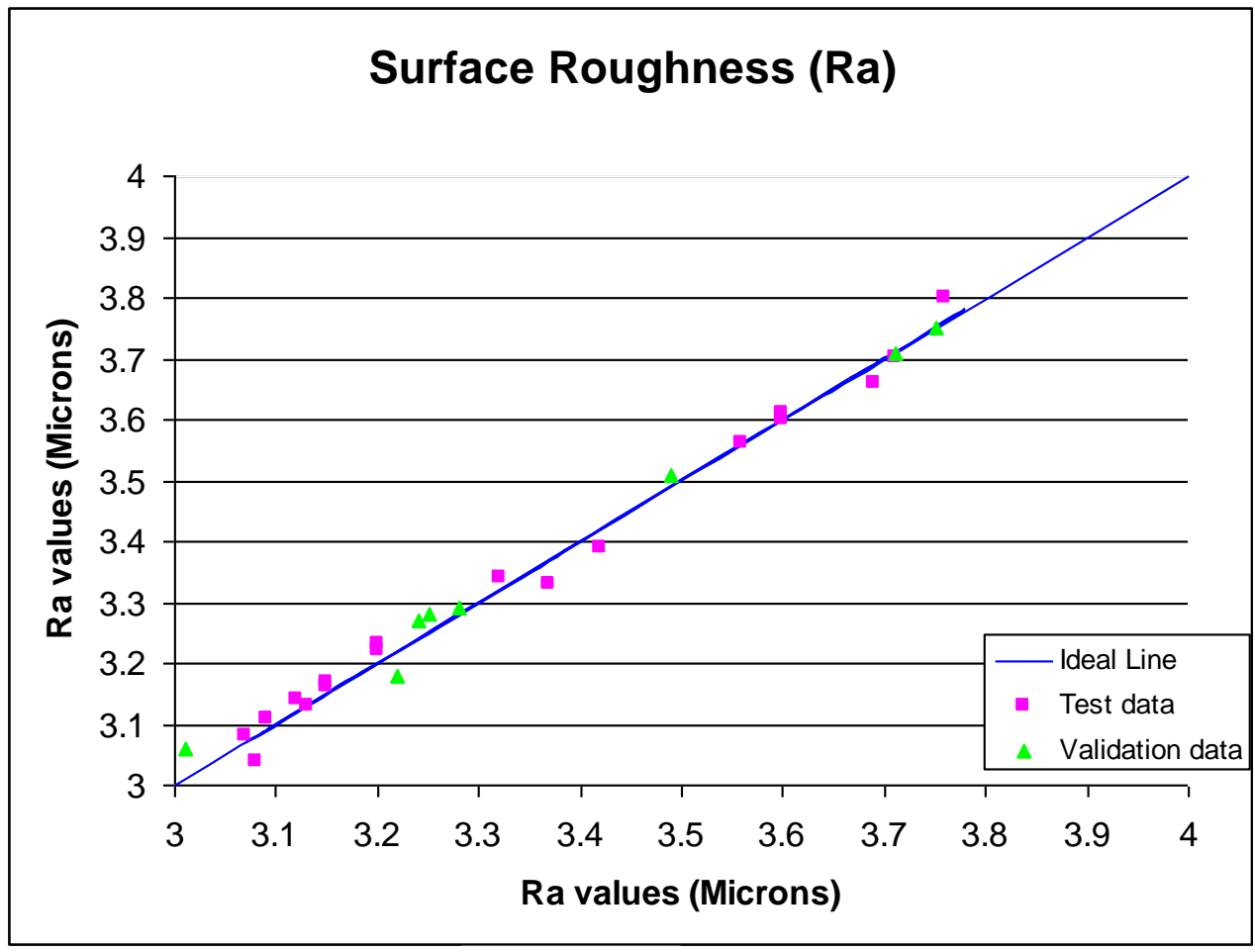

Figure -2 
International Journal of Design and Manufacturing Technology (IJDMT), ISSN 0976 - 6995(Print), ISSN 0976 - 7002(Online) Volume 4, Issue 1, January- April (2013), @ IAEME

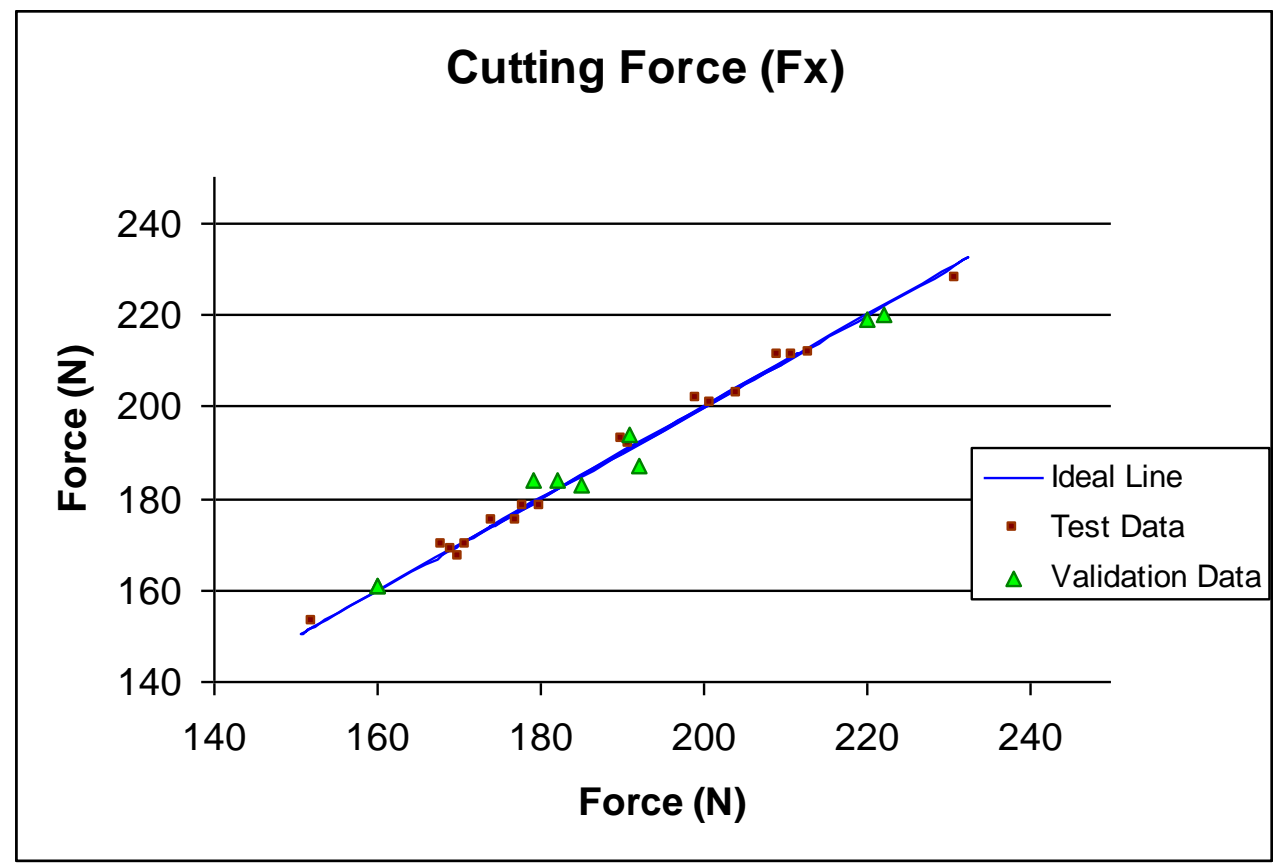

Figure -3

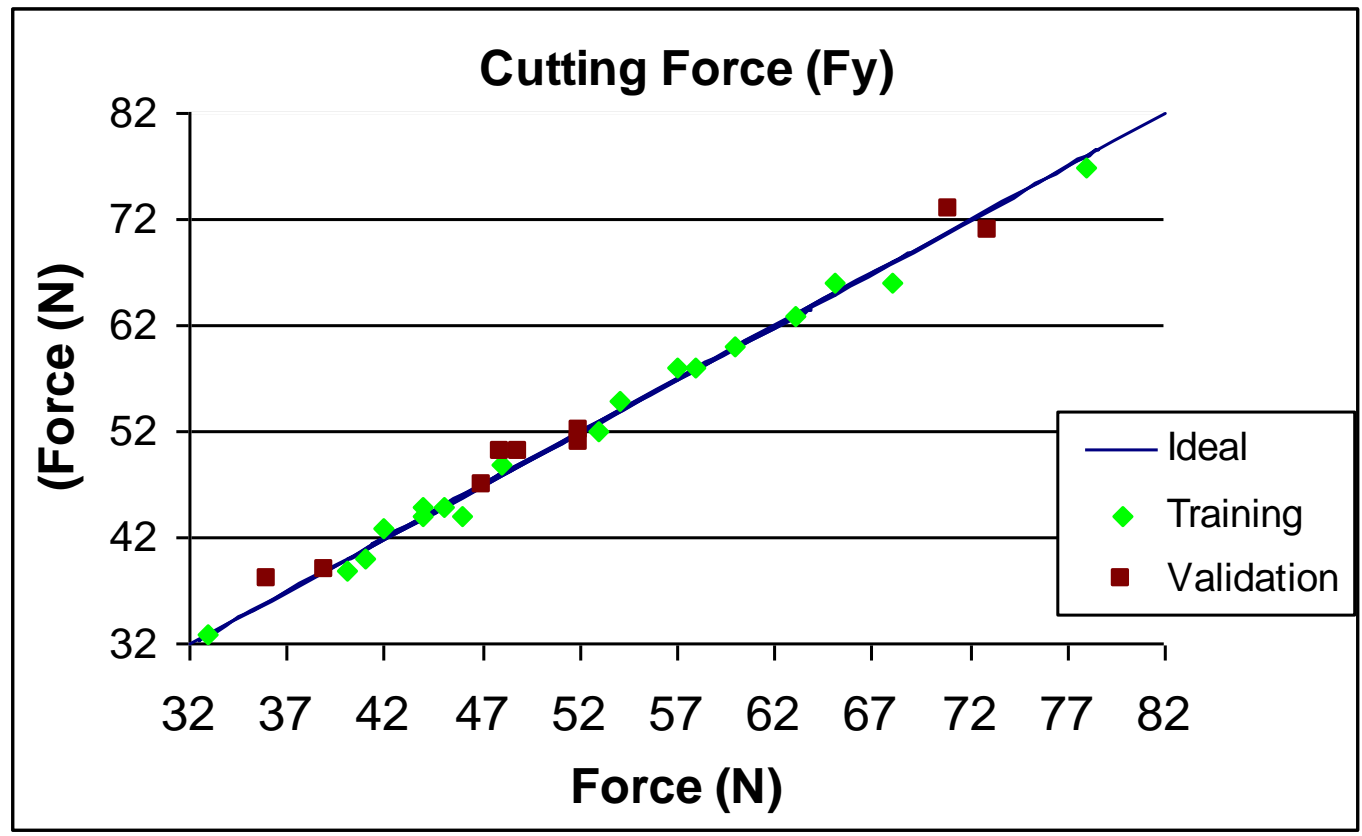

Figure -4

For easy understanding and also for demonstration purposes graphical representations have been made to show the trend of matching of the prediction values with the experimental values for each response, both for the training and validation data-sets. These graphs have been shown in Figure -2 to Figure -5 . 
International Journal of Design and Manufacturing Technology (IJDMT), ISSN 0976 - 6995(Print), ISSN 0976 - 7002(Online) Volume 4, Issue 1, January- April (2013), @ IAEME

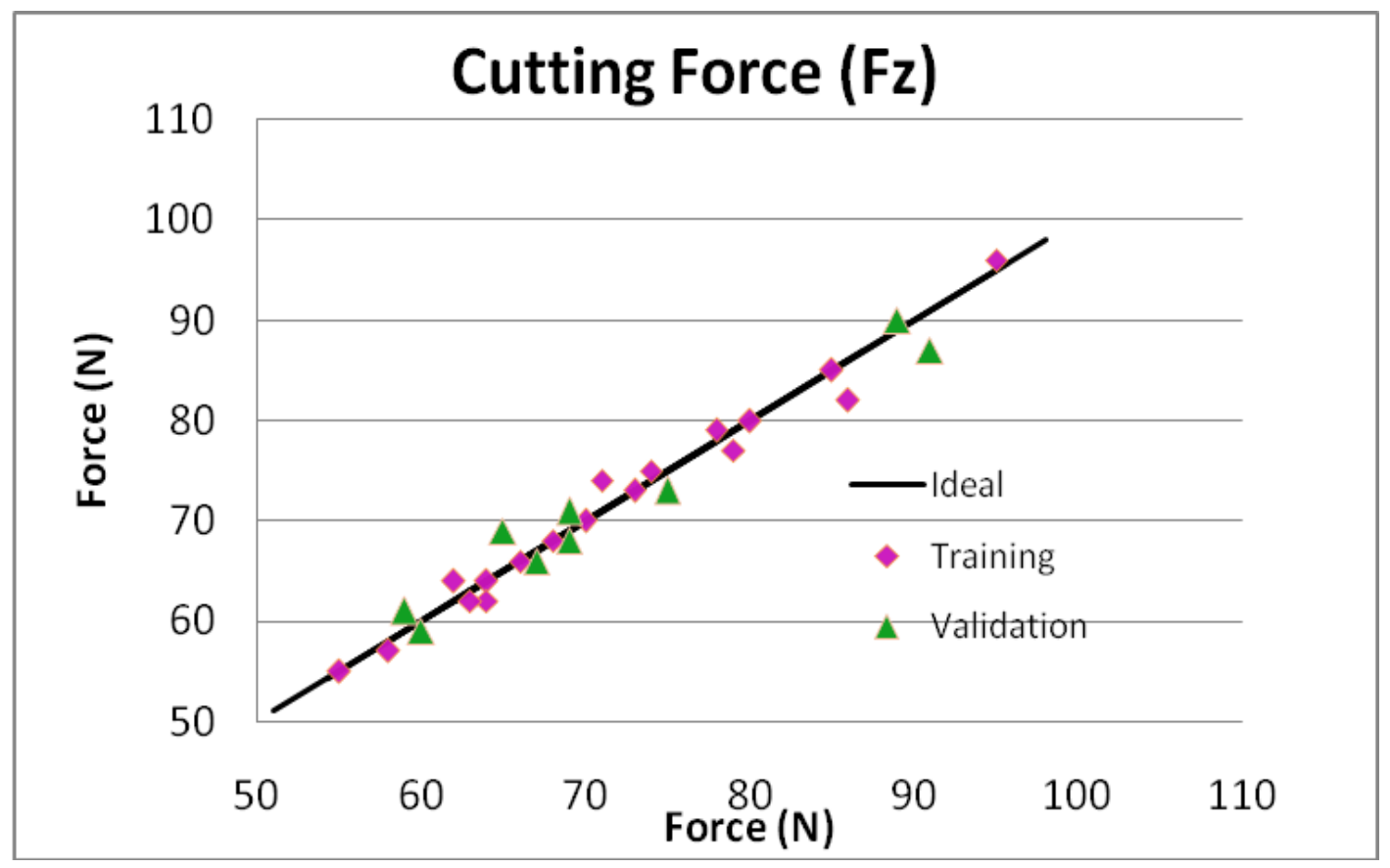

Figure - 5

\subsection{CONCLUSION}

The genetic models developed for machining Inconel 718 alloy by turning process with Coated Carbide tools is having high order of fitness quality within the training data sets and also have good comparison for the validation data sets. Hence the models are found to be dependable and can be used for all practical purposes in the shop floor for choosing the set of machining parameters depending upon the need of the machinist. While considering the experimental test results and also the analytical model results input parameters of $\mathrm{v}=60$ $\mathrm{m} / \mathrm{min} \mathrm{f}=0.2 \mathrm{rpm}$ and $\mathrm{d}=2.0 \mathrm{~mm}$ is considered as optimum set of parameter in terms of achieving moderate MRR combined with lower cutting forces and better surface finish. It is also noted that this set of parameters has a good comparison of predicted values with that of experimental values. Genetic programming is considered to be time consuming since the number of iterations taken is fairly large; however it is worth adopting this method, considering the prediction-accuracy of the model developed both in the case of training and validation purposes. Capability of the genetic models for predicting the responses of a process is extremely good since they have higher accuracy compared to the performance of other analytical methods like ANN, DFA, ANFIS, RSM carried out by the same authors [27-29].

\section{ACKNOWLEDGEMENT}

The research work published in this paper was carried out due to the technical support, guidance and encouragement provided by Vikram Sarabhai Space Centre (ISRO) and National Institute of Technology, Tiruchirappalli. Authors express their hearty thanks to both the Institutions. 
International Journal of Design and Manufacturing Technology (IJDMT), ISSN 0976 - 6995(Print), ISSN 0976 - 7002(Online) Volume 4, Issue 1, January- April (2013), @ IAEME

\section{REFERENCE}

1 J. Bonney, E.O. Ezugwu, Y. Yamane, An overview of the machinability of aero-engine alloy, Journal of Material Processing Technology 135 (2003) 233-253.

2 R.S. Pawade, S.S. Joshi, M. Rahman, High speed machining of 'difficult-to- machine' materials: superalloys - Inconel 718, in: Proceedings of Dyojo on High Speed Machining of Hard/Superhard Materials, NUS Singapore, 7-11 November 2003, pp. 14-28.

3. Liao Y.S, Shiue R.H, Carbide tool wear mechanism in turning of Inconel 718 superalloy, Wear 193(1996), 16 - 24.

4. Sharman A.R.C, Hughes J.I, Ridgway K, An analysis of the residual stresses generated in Inconel 718 when turning, Journal of Materials Processing Technology, 173 (2006), 359367.

5. Ezugwu E.O, Tang S.H, Surface abuse when machining cast iron (G-17) and nickel-base superalloy (Inconel 718) with ceramic tools, Journal of Materials Processing Technology 55 (1995), 63-69.

6. Risbood KA, Dixit US, Sahasrabudhe AD. Prediction of surface roughness and dimensional deviation by measuring cutting forces and vibrations in turning process. Journal of Material Processing Technology, 132 (2003), 203-14.

7. M. Field, J.F. Kahles, W.P. Koster, Surface Finish and Surface Integrity, ASM Handbook, vol. 16, Machining, 9th ed., ASM Publication, ASM, Metal Park, Ohio, 1989.

8. Sandvik, Modern Metal Cutting, Sandvik Coromant, Sweden, 1994.

9. R.S. Pawade, Suhas S. Joshi, P.K. Brahmankar, M. Rahman, An investigation of cutting forces and surface damage in high-speed turning of Inconel 718, Journal of Materials Processing Technology 192-193 (2007) 139-146

10. I.A. Choudhury, M.A. El-Baradie, Machinability assessment of Inconel 718 by factorial design of experiment coupled with response surface methodology, Journal of Materials Processing Technology 95 (1999) 30-39

11. K. Palanikumar, Application of Taguchi and response surface methodologies for surface roughness in machining glass fiber reinforced plastics by PCD tooling, Int. Journal of Advanced Manufacturing Technology 36 (2008) 19-27

12. J. Paulo Davim, Francisco Mata, Optimisation of surface roughness on turning fibrereinforced plastics (FRPs) with diamond cutting tools, Int. Journal of Advanced Manufacturing Technology 26 (2005) 319-323

13. Taraman.K, Multi machining output - Multi independent variable turning research by response surface methodology, International Journal of Production Research, 13(4), 265290, (1975).

14. J. Paulo Davim, Pedro Reis, Machinability study on composite (polyetheretherketone reinforced with $30 \%$ glass fibre-PEEK GF 30) using polycrystalline diamond (PCD) and cemented carbide (K20) tools Int. Journal of Advanced Manufacturing Technology 23 (2004) 412-418

15. George PM, Raghunath BK, Manochac LM, Warrier AM, EDM machining of carboncarbon composite-a Taguchi approach. Journal of Material Processing Technology, 145 (2004) 66-71.

16. Ross PJ, Taguchi techniques for quality engineering, McGraw- Hill, New York, (1996).

17. Montgomery D.C, Design and Analysis of Experiments, John Wiley and sons, New York, (1991).

18. Brezocnik.M, Kovacic.M and Ficko.M, Prediction of surface roughness with genetic programming, Journal of Materials Processing Technology, 157-158 (2004), 28-36. 
International Journal of Design and Manufacturing Technology (IJDMT), ISSN 0976 - 6995(Print), ISSN 0976 - 7002(Online) Volume 4, Issue 1, January- April (2013), @ IAEME

19. Cevdet Gologlu \& Yenal Arslan, Zigzag machining surface roughness modelling using evolutionary approach, Journal of Intelligent Manufacturing, 20 (2009), 203-210.

20. Satyanarayana.B, Ranga Janardhana.G, Kalyan.R.R and Hanumantha Rao.D, "Prediction Of Optimal Cutting Parameters For High Speed Dry Turning Of Inconel 718 Using Gonns" International Journal of Mechanical Engineering \& Technology (IJMET), Volume3, Issue3, 2012, pp. 294 - 305, Published by IAEME

21. Prof. Mohammed Yunus, Dr. J. Fazlur Rahman and S.Ferozkhan, "A Genetic Programming Approach For The Prediction Of Thermal Characteristics Of Ceramic Coatings" International Journal Of Industrial Engineering Research And Development (IJIERD), Volume2, Issue1, 2011, pp. 77 - 89, Published by IAEME

22. Mohammed Yunus, Dr. J. Fazlur Rahman and S.Ferozkhan, "Evaluation Of Machinability Characteristics Of Industrial Ceramic Coatings Using Genetic Programming Based Approach" International Journal of Mechanical Engineering \& Technology (IJMET), Volume2, Issue2, 2011, pp. 126 - 137, Published by IAEME

23. Mohammed Yunus, Dr. J. Fazlur Rahman and S.Ferozkhan, "Prediction Of Optimal Cutting Parameters For High Speed Dry Turning Of Inconel 718 Using Gonns" International Journal of Mechanical Engineering \& Technology (IJMET), Volume3, Issue1, 2012, pp. 294 - 305, Published by IAEME

24. Feng CX. An experimental study of the impact of turning parameters on surface roughness. In: Proceedings of the 2001, Industrial Engineering Research Conference, Paper No. 2036.

25. M. Alauddin , M.A. Mazid , M.A. El Baradi , M.S.J. Hashmi, Cutting forces in the end milling of Inconel 718, Journal of Materials Processing Technology 77(1998) 153 - 159.

26. Ersan Aslan, Necip Camuscu, Burak Birgoren, Design optimization of cutting parameters when turning hardened AISI 4140 steel $(63 \mathrm{HRC})$ with $\mathrm{Al}_{2} \mathrm{O}_{3}+\mathrm{TiCN}$ mixed ceramic tool, Materials and Design 28, 1618 - 1622,(2007).

27. M.Manohar, T.Selvaraj, D.Sivakumar, R. Jeyapaul, Jomy J, Application of Experimental Design and Analysis of Mathematical Models for turning Inconel 718 using Coated Carbide Tools, Experimental Techniques (Wiley \& Blackwell Publishers) 'Accepted' \& Awaiting print version.

28. M Manohar, Jomy Joseph, T Selvaraj, D Sivakumar, Application of Desirability-function and RSM to optimize the multi-objectives while turning Inconel 718 using coated carbide tools, International Journal of Manufacturing Technology and Management (under review)

29. M Manohar, Jomy Joseph, T Selvaraj, D Sivakumar, Application of Box Behnken design to optimize the parameters for turning Inconel 718 using coated carbide tools, 'Optimisation \& Engineering' (Springer Publications) - under review. 